\title{
Psicanálise, Saúde Mental e Universidade
}

\section{Psychoanalysis, Mental Health and University}

\section{Doris Luz Rinaldi* ${ }^{*}$}

Professora Adjunta do Instituto de Psicologia da Universidade do Estado do Rio de Janeiro - UERJ, Rio de Janeiro, RJ, Brasil

\section{Sonia Alberti**}

Professora Adjunta do Instituto de Psicologia da Universidade do Estado do Rio de Janeiro - UERJ, Rio de Janeiro, RJ, Brasil

\begin{abstract}
Resumo
Comemorando dez anos de funcionamento, o Programa de Pós-graduação aqui analisado justifica e se pergunta, através das penas de sua primeira e de sua atual coordenadora, como e até que ponto vem atingindo um dos objetivos declarados em sua Deliberação e que o diferenciaria: associar, na medida do possível, as questões-objeto de pesquisa no campo da psicanálise com problemas socialmente relevantes, fazendo com que a produção e o avanço obtidos através das atividades de pesquisa retornem ao corpo social concreto interessado nessas questões. Verifica-o analisando as dissertações produzidas, assim como parte de sua produção.

Palavras-chave: Psicanálise na universidade, Psicanálise e saúde mental, Pesquisa em psicanálise, Política, Ética.
\end{abstract}

\begin{abstract}
Commemorating its ten years, the Program for post-graduates which is here analysed, justifies and questions through the writing of both its first and its present directors, in what extent have we been attending to one of its objectives for which it is said distinguished: as much as possible, to connect the research object-questions in the field of psychoanalysis with relevant social problems, in order to provide the concrete social body with the results and improvements obtained through research activities. Said improvements are verified through dissertations as well as other bibliographic productions.

Keywords: Psychoanalysis and university, Psychoanalysis and mental health, Research in psychoanalysis, Politics, Ethics.
\end{abstract}

O Programa de Pós-graduação em Psicanálise do Instituto de Psicologia da UERJ, desde sua fundação em 1998, vem sustentando um trabalho de 
ensino com base na íntima articulação entre teoria, pesquisa e prática clínica. No campo da psicanálise há uma indissociável relação entre saber teórico e prática clínica, esta última situando-se não como lugar de aplicação de saber, mas fundamentalmente como lugar de produção desse saber.

Ora, se a produção do saber se dá na prática clínica, então necessariamente toda pesquisa é clínica. Como consequência, a clínica é o lócus privilegiado da pesquisa em psicanálise. Com efeito, desde que foi idealizado, a tônica que diferencia nosso Programa é o peso que damos a essa articulação - tanto que nomeamos sua área de concentração Pesquisa e Clínica em Psicanálise - visando à formação de nossos pós-graduandos de forma a instrumentalizá-los para a vida acadêmica, e também oferecer sustentação de pesquisa para o trabalho no campo da saúde mental que, já dizíamos em nosso projeto, está bem além do consultório do psicanalista.

Nessa direção, seguimos a orientação freudiana formulada em um de seus escritos técnicos, "Recomendações aos médicos que exercem a psicanálise", onde Freud sustenta que a clínica é o solo da pesquisa em psicanálise, ao dizer que: "A psicanálise faz em seu favor a reivindicação de que em sua execução tratamento e investigação coincidem" (FREUD, 1913/1969, p. 152). A pesquisa de que se trata, contudo, é particular, já que a clínica é sempre singular e diz respeito a cada caso. Isto impõe determinada orientação ética à pesquisa que a afasta de todo e qualquer tipo de experimentalismo. Não são poucas as advertências de Freud quanto ao perigo de subordinarmos a clínica à pesquisa, a partir de propósitos científicos que poderiam criar expectativas de controle da experiência clínica.

A pesquisa em psicanálise difere, portanto, daquelas que derivam da proposta nos anos 1950, de Kurt Lewin: a pesquisa ação. Metodologia criada no campo da educação, mas que teve ampla aplicabilidade nos anos 1980 e 1990 (THIOLLENT, 1992), foi definida por Dickens; Watkins (1999), como “uma espécie de 'guarda-chuva' para abrigar várias atividades que pretendem promover mudança no grupo, seja nas organizações ou nos demais segmentos da sociedade". A partir da definição de Lewin, várias outras subsequentes enfatizaram aspectos diferentes do processo de pesquisa ação, mas Argyris; Schon, (1991, p. 86) deixam claro que as intervenções são uma manipulação experimental - não sem terem como meta a resolução do problema no início postulado. Tal perspectiva evidencia a impossibilidade da associação entre pesquisa clínica em psicanálise e pesquisa ação, metodologia particular e aplicada no contexto da pesquisa experimental. Para Lewin a pesquisa ação se consistiu num ciclo de análise, fato achado, concepção, planejamento, execução e mais fato-achado ou avaliação, de modo que, uma repetição 
deste círculo inteiro de atividades, acaba por promover realmente uma espiral de tais círculos, sempre de forma experimental.

$\mathrm{Na}$ clínica psicanalítica, ao contrário, não há nada experimental. O que a norteia não é o controle da experiência, mas uma ética, definida na sua particularidade como a ética da psicanálise. Isso não desmerece nem uma nem outra, mas marca a diferença. De um lado, a psicanálise implica a singularidade do caso a caso e esta diz respeito ao sujeito lá onde ele emerge, no campo do inconsciente, exemplificando a transferência a cada vez que acontece; daí não haver psicanálise fora do contexto transferencial a ponto de não se poder falar nada desse campo clínico sem que o resgate dos dados se dê na transferência. De outro lado, ela implica a política da psicanálise, definida por Lacan em 1958 como a da falta-aser, base de orientação da direção do tratamento, identificada no lugar em que atua aquele que sustenta essa clínica - o psicanalista. Tal política converge com a observação de Freud no escrito citado acima, quando diz que o psicanalista deve conduzir o tratamento "sem pressuposições" e "sem qualquer intuito em vista", permitindo-se "ser tomado de surpresa por qualquer reviravolta neles" (Idem, p.153). Nessa perspectiva, como abertura ao imprevisível da clínica, a prática (ou a práxis, a um só tempo clínica e teórica) do psicanalista se exerce necessariamente, por razões de estrutura, na dimensão da pesquisa, queira o psicanalista reconhecê-lo ou não. A pesquisa é, portanto, uma dimensão essencial da práxis analítica, em função de sua articulação intrínseca, e não circunstancial, com o inconsciente. Mas ela é, por definição também, imprevisível, o que impede quaisquer pressupostos que norteariam uma ida ao campo conforme a pesquisa-ação... Eis o desafio que se colocou para esse Programa e ao qual vimos tentando responder desde sua fundação.

Oferecer sustentação de pesquisa para o trabalho clínico da psicanálise no campo da saúde mental num curso de pós-graduação stricto sensué a proposta que ora apresentamos para preparar o balanço de seus primeiros dez anos de funcionamento. Razão de estarmos ambas apresentando esse trabalho: a primeira coordenadora do Programa e a coordenadora atual.

\section{O projeto}

Por ocasião do projeto que deu origem ao Programa, foram propostas algumas finalidades que dão a orientação necessária para a sustentação de uma pós-graduação stricto sensu voltada para a efetiva relação entre ensino, pesquisa e clínica no campo da psicanálise. Tal orientação dá a marca de uma especificidade que o Programa visa sustentar desde então. No Projeto, então, lê-se, entre as finalidades do Programa que: além de se propor a formar docentes de ensino superior e pesquisadores na área da Psicanálise; estabelecer e manter intercâmbio com a comunidade 
científica, integrada por outros Programas, de forma a manter aberto o debate intra e interdisciplinar necessário ao avanço do conhecimento e tendo na Universidade um lugar que desempenha relevante função nesse debate; tomar como tema-objeto de pesquisa questões relevantes do campo da Psicanálise, questões que venham exigindo atenção por parte dos pesquisadores deste campo de modo a possibilitar a produção de saber necessária ao seu avanço e às suas possíveis soluções; o Programa visará procurar associar, na medida do possível, as questões-objeto de pesquisa em nosso campo com problemas socialmente relevantes, fazendo com que a produção e o avanço obtidos através das atividades de pesquisa retornem ao corpo social concreto interessado nessas questões. Desse modo, o conhecimento produzido poderá vir a ser utilizado por aqueles a quem cabe a elaboração e a implementação de iniciativas de intervenções concretas no campo considerado ${ }^{1}$.

É esse último ponto das finalidades do Programa, em articulação com todos os outros acima enunciados, que buscaremos verificar a fim de avaliar a eficácia dessa proposta e, caso encontrada, estudar seus desenvolvimentos nos últimos dez anos.

Por mais estranho que isso possa soar para muitos, a relação da psicanálise com a universidade é praticamente original: em 1900, Freud publica a Interpretação dos sonhos, obra princeps da psicanálise; dois anos depois é nomeado, pelo Imperador Francisco José, da Áustria, Professorextraordinarius, na Universidade. No entanto, devido à importância que foi adquirindo a história do movimento psicanalítico com suas associações e sociedades -, cada vez mais também em nível internacional, pouco se escreveu sobre a relação da psicanálise com a universidade.

Em 1999, em Paris, em sua fala de abertura dos Estados Gerais da Psicanálise, Elisabeth Roudinesco, uma das mais importantes historiadoras da psicanálise da atualidade, surpreendeu com a observação: é no Brasil que hoje melhor se verifica o desenvolvimento da psicanálise na Universidade, em particular, nos Institutos de Psicologia (informação verbal). Para ter alçado tal reconhecimento internacional, certamente a determinação histórica do lugar da universidade no Brasil deve ter contribuído de alguma maneira, mas contribuíram também a formação e o investimento dos psicanalistas brasileiros que estão hoje nas universidades. Em primeiro lugar, sua formação psicanalítica, que Freud identificava, antes de mais nada, com a análise pessoal de cada um e que permite a transmissão do que propriamente é a causa freudiana; em segundo lugar, sua articulação com a política da psicanálise (cf. ALBERTI, 2008), conceito bastante complexo que visa a observação da singularidade de cada sujeito, e que encontra lugar privilegiado, justamente, na articulação com os avanços das políticas de saúde mental de forma geral, e, em terceiro lugar, o interesse acadêmico sustentado 
por uma política dos órgãos de fomento à pesquisa (CAPES, CNPq e Fundações estaduais) que permitiu o investimento bastante democrático, nos últimos vinte anos, em mestrados e doutorados tanto no Brasil quanto no exterior.

Foi durante os movimentos de 1968 que Lacan criou, com a ajuda de alguns amigos - entre os quais Lévi-Strauss e Michel Foucault -, o primeiro Departamento de Psicanálise na Universidade com a "missão de ensino superior e pesquisa", visando transmitir tanto os saberes que emanam da experiência psicanalítica quanto os que lhe são conexos, já que o saber freudiano não é redutível a um corpo de doutrina fechado e definitivamente constituído. Oficialmente recebida na universidade como uma das respostas aos movimentos de 1968, a psicanálise selava novos tempos e foi nessa mesma orientação que iniciamos nosso trabalho, o que já se demonstra na publicação de nosso primeiro livro $\underline{2}$. Aposta também inovadora no sentido de explorar este binômio: clínica e pesquisa em psicanálise.

Quisemos, em razão de nossas práticas anteriores que, como toda prática, se vinculam com a ética e a política, articular a esse campo da pesquisa, aquele da saúde mental. Trabalhávamos em hospitais, postos de saúde, instituições jurídicas, participávamos de projetos de criação de CAPS ou os supervisionávamos, assim como do movimento da luta anti-manicomial que ganhava cada vez mais espaço, e supúnhamos a possibilidade de instrumentalizar clinicamente o trabalho institucional sem abrir mão do que orienta, de forma mais radical, a relação de cada clínico com a causa freudiana. Poder orientar projetos norteados por isso era, e ainda é, um grande desafio.

É preciso levar em conta o fato de que a "psicanálise pensa o sujeito, em sua raiz mesma, como social, como tendo sua constituição articulada ao plano social" (ELIA, 2004, p.38), e que "o faz de modo positivo, ou seja, de modo a manter a positividade de sua concepção de sujeito do inconsciente, sem o que deixaria de ser psicanálise e se diluiria em meio à polifonia da orquestra das concepções culturalistas de uma construção social do sujeito, que o destitui precisamente de sua positividade como sujeito do inconsciente" (idem, p.22). É só levando isso em conta que, por consequência lógica, estamos verdadeiramente sustentados nos fundamentos da teoria psicanalítica e, ao mesmo tempo, demonstrando a importância da psicanálise como instrumento de intervenção no campo assistencial. Como observa por exemplo Sueli Minatti (2004) quando relata seu trabalho numa instituição que acolhe pessoas com doenças graves, preferencialmente crianças: no trabalho na instituição "está a psicanálise, representada, nesse contexto, pela psicanalista presente na instituição e, sobretudo, pela teoria psicanalítica, que possibilita um movimento dialético entre o fato e o relato do fato" (Idem:22). Como psicanalista "representando" a psicanálise na instituição "e, 
sobretudo, pela teoria psicanalítica", deve-se então, nesse campo, fazer valer o que há de mais genuíno no cidadão: sua própria subjetividade, determinada como é pelas leis da linguagem, pelo inconsciente, pela divisão subjetiva.

\section{A ênfase}

De forma privilegiada, temos investigado e discutido as questões oriundas da prática clínica da psicanálise justamente onde ela encontra maiores desafios - a instituição pública de saúde e de saúde mental, a instituição de reabilitação, a instituição penitenciária, entre outros campos clínicoinstitucionais. As diversas pesquisas que desenvolvemos nessas esferas têm produzido avanços no campo próprio do estudo da psicanálise e na formação de nossos alunos, mas também têm seus efeitos nas práticas profissionais desenvolvidas nessas instituições. Exemplos disso são as pesquisas que abordam a clínica que se desenvolve nas instituições públicas em saúde mental, em particular nos Centros de Atenção Psicossocial (CAPS) que, pelas questões que discutem, vêm contribuindo para levar os próprios agentes institucionais a uma reflexão sobre as suas práticas. Sem contar que muitos de nossos alunos estão inseridos nessas instituições sustentando uma prática clínica orientada pela psicanálise e, portanto, tornando efetiva a integração com o campo social, que tanto valorizamos. A participação de alunos dos diversos níveis - desde a graduação até a pós-graduação - em nossas pesquisas tem sido fundamental para formar profissionais qualificados e engajados no trabalho nas instituições públicas, assim como para ampliar o alcance social da psicanálise. Além disso, a participação de docentes na supervisão de trabalhos clínicos nas instituições é mais um elemento que evidencia a inserção social de nosso Programa.

Alguns dados permitem visualizar melhor o trabalho que desenvolvemos nessa direção. Do conjunto de 105 dissertações defendidas em nosso Programa até agora, 57 abordam, de uma forma ou outra, os desafios da clínica nas instituições, o que representa um total de mais de $50 \%$ (cinquenta por cento). Duas delas já foram publicadas como livros: A Guarda dos Filhos na Família em Litígio - uma interlocução da Psicanálise com o Direito, de autoria de Lenita Pacheco Lemos Duarte ${ }^{3}$ e Capsi para crianças e adolescentes autistas e psicóticos: a contribuição da psicanálise na construção de um dispositivo clínico, de autoria de Rosemary Fiães Pinto ${ }^{4}$, esta premiada no concurso Carlos Gentile do Museu da República em 2006.

Os temas dessas 57 dissertações variam entre: a clínica nos CAPS (de adultos, CAPSis e CAPSad); as contribuições da psicanálise às práticas hospitalares; o atendimento e as questões subjetivas que surgem no 
trabalho de ambulatórios em diversas instituições, desde as religiosas, as jurídicas (escolas para menores em conflito com a lei, manicômios judiciários, assistência a juízes em questões familiares e de adoção), escolas, postos de saúde; o discurso psicanalítico e o psiquiátrico em unidades de atendimento psiquiátricas, em residências terapêuticas; o que pode a psicanálise na clínica das deficiências? (deficiências físicas, debilidade mental); a psicanálise na assistência ao idoso em instituições. O título de uma dissertação resume bem a questão e a aposta: "Miséria neurótica ou desejo inédito, por onde "escolhemos" transitar? Construções com uma população de baixa renda", de Daniela Goulart Pestana, defendida em julho de 2003, sob orientação da Professora Doris Rinaldi. Texto no qual cada cidadão, independente de sua posição sócioeconômica, pode ser tomado como sujeito, construir algo em seu tratamento que o assegure desse lugar de sujeito, a partir da possibilidade que a psicanálise oferece de que ele advenha de um desejo inédito, na contramão da posição queixosa de uma miséria que, por mais que seja muitas vezes social e econômica acaba por imiscuir-se na neurose que cristaliza, por sua vez, a miséria ${ }^{5}$.

Dos vários projetos de pesquisas desenvolvidos pelos docentes que abordam essas questões, diversos artigos vêm sendo publicados em revistas especializadas e dois dos livros organizados pelo Programa são totalmente dedicados a elas: Psicanálise, Clínica e Instituição, Altoé, S. e Lima, M. M. (orgs), Rio de Janeiro, Rios Ambiciosos, 2005 e Psicanálise e Saúde Mental: uma aposta, Alberti, S. e Figueiredo, A. C. (orgs.), Rio de Janeiro, Companhia de Freud, 2006. O primeiro resulta da reunião de uma série de artigos produzidos por nossos professores e alunos sobre a clínica psicanalítica na instituição e o segundo é o produto das elaborações que se seguiram ao evento "Psicanálise e psicoterapia no campo da saúde mental", organizado por nosso Programa em parceria com o Programa de Pós-graduação em Psicologia Clínica da PUC/Rio e com o IPUB/UFRJ $\underline{6}$. $\mathrm{Na}$ "Apresentação'" desse último lemos que a proposta que deu origem ao livro teve como objetivo principal

associar psicanalistas, professores, pesquisadores universitários e trabalhadores da saúde, na urgente tarefa de identificar, aprofundar, debater e especificar o que é o trabalho psicanalítico no campo da saúde mental hoje, articulando-o e diferenciando-o de outras práticas psicoterápicas no intuito de sublinhar sua especificidade na contribuição para a sustentação do paciente e usuário dos serviços como sujeito (ALBERTI; FIGUEIREDO, 2006, p.14).

A partir de nossas produções - das quais demos aqui algumas referências e que ainda incluem o número especial da Revista Estudos e Pesquisas em Psicologia "Dossiê psicanálise" (2008) -, interessa-nos trazer para a discussão as articulações que temos feito em torno do binômio políticas de 
saúde mental e teoria da clínica em psicanálise. Privilegiaremos a inserção do dispositivo psicanalítico no campo da atenção psicossocial, campo esse que se constituiu a partir da reforma psiquiátrica brasileira.

A reforma psiquiátrica brasileira reconfigurou o quadro da assistência em saúde mental no País, ao colocar em questão os tradicionais dispositivos de tratamento da loucura, construindo novos dispositivos de assistência. Ao problematizar a hegemonia do saber médico nesse campo, ela abriu espaço para a construção de novas formas de abordar o sofrimento psíquico, propondo um trabalho multidisciplinar que reorienta a prática clínica nos serviços públicos de saúde. A luta pela cidadania do louco constitui-se como a sua principal bandeira, dando a este movimento um caráter político que marca as reformulações no âmbito das políticas públicas e das instituições, tendo seus efeitos sobre a clínica propriamente dita. O campo da atenção psicossocial caracteriza-se por diferentes orientações; desde aquelas que, oriundas da psiquiatria democrática italiana, privilegiam a dimensão política, propondo uma supressão da clínica em prol do cuidado, até aquelas que retomam a clínica, seja incorporando os procedimentos de atenção psicossocial, passando a designá-la como clínica ampliada, clínica do cotidiano e clínica do sujeito, onde se faz notar, nesta última, a presença do discurso psicanalítico (RINALDI, 2005).

Certa tensão necessária entre clínica e política, percebida em nossas pesquisas e já apontada por vários estudiosos, percorre este campo. Falamos de uma tensão necessária porque não pode ser de outro modo: de um lado temos a política pública de saúde mental, que sustenta a reforma no âmbito das instituições, através do estabelecimento de uma série de normas gerais que definem objetivos, competências e formas de gestão, e, de outro, o trabalho efetivo que a equipe de cada serviço desenvolve com a população assistida, que não pode desconsiderar a singularidade de cada sujeito que busca tratamento em virtude de sofrimento psíquico grave. É nessa esfera que a clínica encontra o seu lugar. A tensão entre esses dois aspectos muitas vezes toma o caminho da tentativa de eliminação de um dos pólos, principalmente do pólo da clínica, a partir de uma crítica ao paradigma psiquiátrico tradicionalmente segregador e excludente, que leva de roldão outras orientações clínicas. Ou então uma redução da clínica a procedimentos de reabilitação psicossocial, normatizadores e pedagógicos. Contudo, as pesquisas que se debruçam sobre a prática clínica com a psicose e com as neuroses graves nas novas instituições de saúde mental evidenciam de diversas formas que não é possível sustentar uma política de inclusão e reinserção social de uma população tradicionalmente excluída do laço social, se não empreendermos um trabalho singular com cada sujeito, que leve em consideração a sua forma particular de se endereçar ao Outro. 
É nessa dimensão que a teoria da clínica em psicanálise tem uma contribuição importante a dar, ao precisar o conceito de sujeito a partir dos ensinamentos freudianos, como correlativo do conceito de inconsciente. Quando nos referimos à clínica do sujeito é para essa dimensão que estamos chamando a atenção, o que nos leva a tomar a sua fala não apenas no registro da doença ou da demanda de assistência, mas como índice de sua condição subjetiva. "Dar voz aos pacientes", proposta política da reforma que visa subverter a tradicional ordem médica, onde o saber está no médico e a ignorância no doente, pode ser tomada, assim, sob este outro viés da clínica do sujeito, fundada em uma ética do desejo, que é, sobretudo, uma ética da diferença (RINALDI, 1999). Sustentar a clínica na instituição nessa perspectiva ética - que não é a da moral assistencialista que já sabe de antemão o que é melhor para o sujeito - pode ser pensado também como uma proposta política, na medida em que introduz um fator que não pode ser desconsiderado - o fator sujeito - em um processo que pretende reconstruir as formas de assistência pública à saúde mental, a partir de outros paradigmas.

Partimos da hipótese de que o trabalho no campo da saúde mental é fundamentalmente um trabalho clínico e não há clínica psicanalítica que não se fundamente na teoria da clínica. Suas bases já se encontram nos textos técnicos e nos casos clínicos de Freud e, ao longo dos últimos cem anos, a maior parte dos autores, das mais diferentes escolas psicanalíticas, contribuiu para o debate da teoria da clínica. Não podemos esquecer, além disso, as recomendações de Freud feitas em 1918 no Congresso de Budapeste ${ }^{7}$, em que chama a atenção para a urgência de expansão da oferta da psicanálise para as camadas mais pobres da população, inicialmente através de instituições privadas, mas sobretudo como um dever do Estado, através de instituições públicas. Nesse sentido, o trabalho clínico dos psicanalistas nesse campo tem também uma dimensão política.

Vivemos atualmente um momento de máximo risco frente ao recrudescimento impressionante da foraclusão do sujeito! Diante do que não temos outra saída senão fortalecer nossa prática com atos que se sustentem em nossa teoria, nossa formação de psicanalistas e nossa consequente particularidade ética, ao contrário do que se pensava antes, de que é preciso adaptá-las ao discurso médico para se fazer ouvir. A "formação permanente" dos profissionais da saúde mental é imprescindível e atualmente ainda é "insuficiente na geração de novas posturas éticas, de um novo posicionamento e abertura diante daquele que padece de grande sofrimento psíquico" como observam também Furtado, J.P. e Campos, R.O. (2005, p.114) ao analisarem o campo em que se inscreve atualmente a Reforma Psiquiátrica no Brasil. A contribuição da universidade, ao voltar suas atividades de pesquisa para este campo, é, nesse sentido, inestimável. 
Concluímos que a finalidade do Programa de Pós-graduação em Psicanálise do Instituto de Psicologia da UERJ expressa no início deste artigo como sendo a de "oferecer sustentação de pesquisa para o trabalho clínico da psicanálise no campo da saúde mental", pelo que pudemos verificar no levantamento que realizamos, está bem atendida tanto no que tange às dissertações produzidas (mais de 50\%), quanto nos textos publicados pelo corpo docente e discente que divulgam a preocupação do Programa em articular psicanálise e saúde mental, não só em periódicos como também em livros por nós realizados. Ao mesmo tempo, se pode verificar através da mesma percentagem, que o Programa não se restringe a essas pesquisas, tendo aberto um leque bastante largo para outras questões, tanto em dissertações quanto em projetos de tese - já que há dois anos também contempla candidatos a doutorado. Tal abertura, assim como seu peso em termos de produção, ou seja, em quantidade de dissertações defendidas, não deixou de nos surpreender! Os temas os mais diversos, todos de alguma forma articulados com a clínica psicanalítica, a teoria da clínica ou, até mesmo, em alguns casos, mais puramente teóricos, merecem igualmente a atenção nesse momento em que estamos comemorando nossos primeiros dez anos de funcionamento. Por que houve quase cinquenta por cento de dissertações defendidas que não abordam explicitamente aquela finalidade de se "procurar associar, na medida do possível, as questões-objeto de pesquisa em nosso campo com problemas socialmente relevantes, fazendo com que a produção e o avanço obtidos através das atividades de pesquisa retornem ao corpo social concreto interessado nessas questões", como se lê na Proposta do Programa? A resposta a essa questão está articulada às outras finalidades do Programa igualmente aqui explicitadas, pois certamente essas outras dissertações dizem respeito a se "tomar como tema-objeto de pesquisa questões relevantes do campo da Psicanálise, questões que venham exigindo atenção por parte dos pesquisadores deste campo de modo a possibilitar a produção de saber necessária ao seu avanço e às suas possíveis soluções" (cf. Proposta do Programa), ou seja, testemunha que nosso Programa efetivamente se inscreve na histórica relevância que a universidade tem para a psicanálise desde seus primórdios, dando abertura para o tratamento das mais diversas questões na interlocução entre psicanálise e universidade, em particular a das conexões da psicanálise com a ciência e com a cultura e a arte, pilares que Freud (1927/2009, p. 169-172) e Lacan (1953/1998, pp. 288-290) já haviam constituído como grandes eixos de interlocução da psicanálise na universidade. Podemos dizer, então, que isso lastreia o próprio trabalho que fazemos de pesquisar os problemas socialmente relevantes a partir das contribuições que a psicanálise a eles pode trazer porque a psicanálise com a qual trabalhamos é suficientemente consistente para abordar quaisquer temas, até mesmo aqueles que dizem respeito à sua teoria. Ao 
mesmo tempo, o fato de sustentarmos pesquisas que dizem respeito à psicanálise mas que não são necessariamente voltadas para os problemas socialmente relevantes - e cujas temáticas vão desde as contribuições da matemática à psicanálise até a feminilidade, para citar somente duas -, identifica exceções que acabam por confirmar a regra: o tema mais desenvolvido nas pesquisas do Programa articula psicanálise e problemas socialmente relevantes.

\section{Referências Bibliográficas}

ALBERTI, S. A política da psicanálise e a da saúde mental. In: Revista Estudos e Pesquisas em Psicologia. Ano 8, no. 1. Rio de Janeiro: Instituto de Psicologia da UERJ, $2008 . \quad$ Disponível em: www.revispsi.uerj.br. Acesso em 02 jun. 2009.

ALBERTI, S.; FIGUEIREDO, A.C. Apresentação. In: Psicanálise e saúde mental: uma aposta. Rio de Janeiro: Companhia de Freud, 2006

ARGYRIS, C.; SCHON, D. Participatory Action Research and Action Science Compared. In: W. F. Whyte. Participatory Action Research. Newbury Park: Sage, 1991.

CIAMPA, A. C. A Estória do Severino e a História da Severina. Rio de Janeiro: Civilização Brasileira, 1990.

DICKENS, L.; WATKINS, K. Action research: Rethinking Lewin Management Learning. Thousand Oaks: Geographic Names- US, 1999.

ELIA, L. O conceito de sujeito. Rio de Janeiro, Jorge Zahar, 2004.

FREUD, S. [1913]. Recomendações aos médicos que praticam a psicanálise. In: Edição Standard Brasileira das Obras Psicológicas Completas de Sigmund Freud.Vol. XII. Rio de Janeiro, Imago Editora, 1969. p. 147-159.

. [1919]. Linhas de Progresso na terapia psicanalítica. In: Edição Standard Brasileira das Obras Psicológicas Completas de Sigmund Freud.Vol. XVII. Rio de Janeiro: Imago Editora, 1969. p. 199-211.

- [1927]. Pós-escrito de A Psicanálise leiga. In: ALBERTI, S. et al (org.). Ofício do psicanalista: formação versus regulamentação. Tradução do texto de Freud feita diretamente do alemão por Eduardo Vidal. São Paulo: Casa do Psicólogo, 2009. p. 167-180.

FURTADO, J. P.; CAMPOS, R. O. A transposição das políticas de saúde mental no Brasil para a prática nos novos serviços. Revista Latinoamericana de psicopatologia fundamental, São Paulo, V. VIII, n. 1, março, 2005. Disponível em: www.scielo.br. Acesso em 02 jun. 2009.

LACAN, J. [1953]. Função e campo da fala e da linguagem. In: Escritos. Rio de Janeiro, Jorge Zahar Editor, 1998. p. 238-324. 
. [1958]. A direção do tratamento e os princípios do seu poder. In: Escritos. p. 591-652, Rio de J aneiro, J orge Zahar Editor, 1998. MINATTI, S.P. A criação do campo psicanalítico na instituição. Revista Latinoamericana de psicopatologia fundamental, São Paulo, V. VII, n. 1, março, 2004. Disponível em: www.scielo.br. Acesso em 02 jun. 2009.

Revista Estudos e Pesquisas em Psicologia, Ano 8, n. 1, Rio de Janeiro, 2008. Disponível em: www.revispsi.uerj.br. Acesso em 02 jun. 2009.

RINALDI, D. A ética da diferença: um debate entre psicanálise e antropologia. 2. ed. Rio de J aneiro: Jorge Zahar Editor, 1999.

- Clínica e Política: a direção do tratamento psicanalítico no campo dà saúde mental. In: ALTOÉ, S. de LIMA, M. M. (org.) Psicanálise, Clínica e I nstituição. Rio de Janeiro: Rios Ambiciosos, 2005. p. 87-106. THIOLLENT, M. Metodologia da pesquisa-ação. São Paulo: Cortez, 1992.

\title{
Endereço para correspondência
}

Doris Luz Rinaldi

Universidade do Estado do Rio de Janeiro-UERJ, Rua São Francisco Xavier, 524, Bloco F, 10ㅇaㅁ, Instituto de Psicologia, CEP 20550-013, Rio de Janeiro-RJ, Brasil

Endereço eletrônico: doris_rinaldi@yahoo.com.br.

Sonia Alberti

Universidade do Estado do Rio de Janeiro-UERJ, Rua São Francisco Xavier, 524, Bloco F, 10ㅇaㅁ, Instituto de Psicologia, CEP 20550-013, Rio de Janeiro-RJ, Brasil

Endereço eletrônico: alberti@fcclrio.org.br

Recebido em: 02/10/2008

Aceito para publicação em: 14/04/2009

Editor responsável: Ariane Patrícia Ewald e Deise Mancebo

\begin{abstract}
Notas
* Pesquisadora do CNPq; Psicanalista Membro de Intersecção Psicanalítica do Brasil. É a atual Coordenadora do Programa de Pós-graduação em Psicanálise da UERJ. ** Pesquisadora do CNPq; Psicanalista Membro da Escola de Psicanálise dos Fóruns do Campo Lacaniano. Foi a primeira Coordenadora do Programa de Pós-graduação em Psicanálise da UERJ

1 Deliberação do Programa de Pós-graduação em Psicanálise do IP/UERJ.

2 Alberti, S e Elia, L. (orgs.), Clínica e pesquisa em psicanálise, Rio de Janeiro, Rios Ambiciosos, 2000.

3 DUARTE, Lenita Pacheco Lemos. A Guarda dos Filhos na Família em Litígio - uma interlocução da Psicanálise com o Direito. Rio de Janeiro: Editora Lúmen Júris, 2006. A Dissertação foi orientada pela Professora Sonia Altoé.

4 PINTO, Rosemary Fiães. Capsi para crianças e adolescentes autistas e psicóticos: a contribuição da psicanálise na construção de um dispositivo clínico. Rio de Janeiro: Museu da República, 2007. A Dissertação foi orientada pelo Professor Luciano Elia.
\end{abstract}


5 Cf., por exemplo, A Estória do Severino e a História da Severina, de ANTONIO DA COSTA CIAMPA, publicado pela Civilização Brasileira (1990).

6 II Simpósio do Programa de Psicanálise do Instituto de Psicologia da UERJ - Simpósio Nacional de Psicanálise e Psicoterapia no campo da Saúde Mental (UERJ/IPUB/PUC-RJ), de 31 de agosto a 3 de setembro de 2005.

${ }^{7}$ A conferência pronunciada por Freud nesse Congresso foi publicada em 1919 com o título "Linhas de progresso na terapia psicanalítica". 